\title{
Estimating older people's labour supply decisions in Korea*
}

\author{
INHEE $\operatorname{LEE}^{1}$ and ALMAS HESHMATI ${ }^{2, *}$
}

${ }^{1}$ Department of Economics, Sogang University, Seoul, Korea

2 Jönköping International Business School, Jönköping University, Jönköping, Sweden

Received: September 10, 2019 • Revised manuscript received: February 3, 2020 - Accepted: February 6, 2020

(C) 2020 The Author(s)

\begin{abstract}
In 2017, Korea became an 'aged society,' with the proportion of people aged 65 or older exceeding $14 \%$, while the ratio of the working-age population declined for the first time. This study uses data from the Korean Longitudinal Study of Ageing (KLOSA) to examine the effects of public pension on the labour supply of older people and discusses ways of preparing for this ageing problem. The study uses the Heckman sample selection model for analysing both the extensive and intensive margins of older people's labour supply. Our results show that the effects of public pensions in Korea are very different from that in other countries. It can be inferred that these differences are a consequence of the less developed social security system and limited experience from its short period of implementation. Hence, encouraging older people to work could be a way of solving the problem of relatively high poverty among the older population in a society that is likely to age even more. This is considered an optimal solution in light of increasing life expectancy, a poor social security system, and a decrease in private income transfers from children to their ageing parents.
\end{abstract}

\section{KEYWORDS}

ageing society, public pension, older people labour supply, welfare policy, retirement, Korea

\section{JEL CODES}

H55, H75, J14, J26

\footnotetext{
*Corresponding author. E-mail: almas.heshmati@ju.se

${ }^{\star}$ The authors are grateful to the editors of the journal and an anonymous referee for their comments and suggestions on an earlier version of the manuscript.
} 


\section{INTRODUCTION}

An ageing population is an inevitable phenomenon not only in Korea but also in most Organization for Economic Co-operation and Development (OECD) countries. This increase in the share of the older population could lead to a decrease in the share of the productive population and have a negative impact on these nations' economic growth. In addition, a reduction in the percentage of workers who will be responsible for finances along with an increase in the number of people receiving benefits of the social security system will have a negative impact on the financial stability of the social security system. This, in turn, can lead to problems of poverty among the vulnerable, especially older people. Therefore, how to prepare and cope with an ageing society is an important social issue. In response, most OECD countries have come up with policies since the 1990s to prepare for ageing, including implementing policies that encourage extending the working years for older people beyond the formal retirement age (Gillion 2000).

What is noteworthy in Korea's case is that its ageing rate is much faster compared to other countries, just as its industrialization and economic growth rates were faster as well. Perhaps this high rate of ageing is an effect of economic growth. According to Statistics Korea's 2017 demographic report, Korea's population will continue to decline in the coming years while its older population will exceed 10 million by 2020 when the baby boomers (born between 1955 and 1963) enter the bracket of older population. The problem is that the government does not have enough time for an effective policy response to this ageing issue.

In the absence of a well-developed safety net, after retirement the older population in Korea tends to depend on private support provided by their children and other family members. However, this traditional channel is weakening due to urbanization and demographic changes. Today, pension or government assistance accounts for a small proportion of older people's income, which is a phenomenon in other Asian countries as well (Bang et al. 2005). Therefore, it is important to know how and by how much the low levels of public pensions affect older people's labour supply in Korea. A viable solution that can ease these social problems in preparing for ageing and implementing effective policies could be increasing older people's participation in the labour market. Therefore, an increasing older people labour market participation is a key part of handling the ageing problem in developed countries (Visco 2002). Hence, research on the labour supply of the older population becomes significant. This study analyses older people's work in a reduced form in terms of extensive margins (participation at work) and intensity margins (work supply time).

Various studies have shown that Korea has a relatively high employment rate of older people compared to other OECD countries (Park 2000). The high labour ratio of older people may explain the high labour supply in rural areas. According to Quinn and Kozy (1996), the determinants of retirement are highly influenced by individual choice and spontaneity. The decision on when to retire is determined by the utility of labour supply and leisure. The decision to retire is determined by factors such as income, assets, health conditions, social insurance and human capital when optimizing pension income, labour supply and leisure.

This study considers all these factors and looks at senior citizens' decision-making processes for working and retiring, particularly the impact of public pension on these decisions. Studies in countries that experienced ageing before Korea show that public pension have a significant impact on older people's retirement decisions (Pampel - Weiss 1983). Most of the previous 
studies on the older populations' labour behaviour note the negative impact of pensions on their labour participation. However, previous studies in Korea show that older people are participating in economic activities even after the age of pension (Kwon - Park 2017). This study also verifies the results of previous studies and compares them with examples from other countries.

The rest of this paper is organized as follows. Section 2 looks at the retirement and labour status of the older population in Korea. Section 3 looks at earlier studies on the subject. Section 4 describes the data and the variables used in the study. Section 5 describes the methodology used for the empirical analysis and the models. Section 6 presents the results, while Section 7 summarizes the conclusions and implications of the findings.

\section{CURRENT STATE OF OLDER PEOPLE'S LABOUR SUPPLY IN KOREA}

The OECD measures the ageing process using the old-age dependency ratio, which measures the number of those aged above 65 years as a share of the working age population. According to OECD data, the old-age dependency ratio is expected to increase from the OECD average of 27.9 in $2015-58.8$ in 2075 and more than quadruple from 19.4 to 78.8 in Korea.

Figure. 1 shows estimates of Korea's future population divided by the working age population and older population aged 65 and older. The UN categorizes a society as an ageing society in which people over 65 make up more than $7 \%$ of the total population; $14 \%$ as an aged society; and $20 \%$ as a super-aged society. As mentioned earlier, Korea became an ageing society in 2017, and is expected to become a super-aged society in 2025. Figure. 1 shows that the working age population will continue to decline while the number of older people will continue to increase. In particular, the large increase in the proportion of baby boomers in the working age population in the 1970s and 1980s will lead a rapid increase in the ageing population in 2025.

One encouraging fact is that in Korea the employment rate among older people (55-64 years) is higher than the OECD average. Figure. 2 shows the employment rate among the older population in Korea and major OECD countries over the last five years. In Korea, the

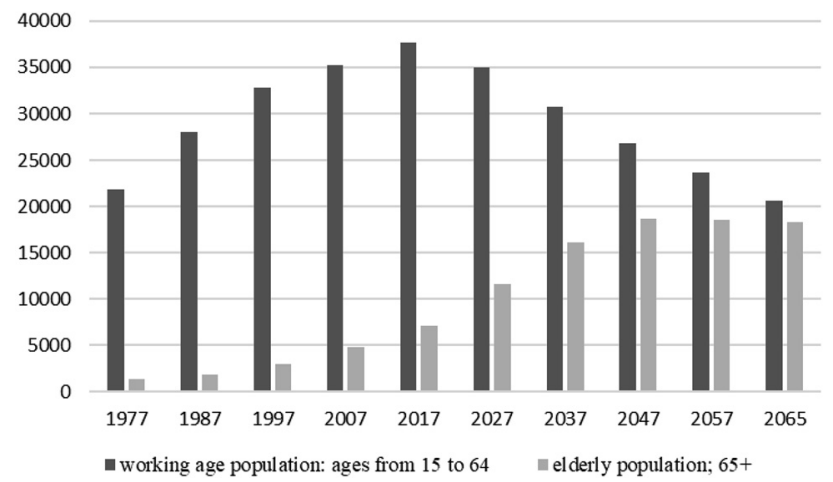

Figure 1. Estimated population in Korea (by age)

Source: OECD Statstics, Demography and Population 
employment rate of the aged population in the mid-1960s was higher than the OECD average and in the US, but lower than that in some East Asian countries. Japan is expected to be the most ageing society currently followed by Sweden, which is one of the most advanced welfare societies. This shows that Korea can reach a high level of labour market participation for older people as in the advanced countries such as Sweden and Japan, where social security is advanced and at a level that Korea can target.

Encouraging work participation among the older population is a way of maintaining the desired size of the country's workforce. It is also an important way of easing the problems of an ageing society in terms of reducing the actual old-age dependency ratio, and the economic dependence of the older population on society and the younger population. South Korea already has a high employment rate among older people, but it still needs to consider higher levels of employment as seen in Sweden and Japan. These countries have increased their retirement age. With no public support like a public pension, which guarantees minimum living standard for everyone, Korea is expected to incur a high old-age dependency ratio.

\section{LITERATURE REVIEW}

Prior studies on labour among older populations, or retirement studies, mostly discuss the impact of public or private pensions on retirement (Feldstein 1974; Iams 1987; Pampel - Weiss 1983). Some studies mention the effect of pension on early retirement (Purcell 2000; Quinn 1999), while others regard retirement as a voluntary choice (Hurd - Boskin 1984; Quinn - Burkhauser 1994). These studies use the traditional labour supply model. Many studies on Korea too, discuss the impact of public pension on labour participation among older people (Kang 2015; Jeon 2010; Park 2003). Following Qiu (2007); Heshmati (2018) views ageing in China as a 'ticking time bomb' and healthy ageing as a solution for diffusing it.

According to Suk and Kim (2000), non-wage income affects retirement decisions more in Korea. This is in contrast to the high percentage of public transfer income in developed countries such as Germany and the US. Their research does not explain the current situation because it uses older data. However, in Korea, which showed a high proportion of private transfers, this share is gradually decreasing and the proportion of public transfers is gradually increasing.

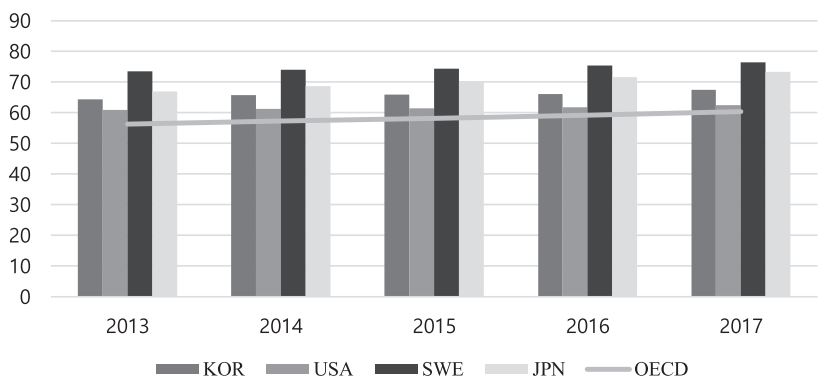

Figure 2. Employment rate among the older population in developed countries Source: OECD Statstics, Demography and Population 
Korea's public pension system, the National Pension Service, started somewhat later than it did in other OECD countries, and there is little research on pension and labour in the country. However, the receipts began in 2008 and many studies related to public pension were conducted in the 2000s (Bang et al. 2005; Kim 2018; Shin - Yang 2003; Song - Park 2012). However, even though there are many studies on labour and retirement among the older population, it is hard to find a study that considers the sample selection bias in a study of labour supply. We use the Heckman two-step sample selection method accounting for differences in older individuals' probability of labour participation.

According to a study by Gruber and Wise (1997), which covers a variety of advanced European countries, the United States and Japan, social security systems affected a decline in labour market participation rates in most countries, especially in Germany and France. In a study of 25 European countries, Hinrichs and Aleksandroicz (2006) observed that the labour market participation rate of older people averaged only $35.8 \%$ compared to a decade ago, which was related to the exodus of the aged population due to the creation of public pension systems since the 1960s. Osberg (1993) analysed Canadian data using the Heckman model and showed the importance of the older population's participation in labour. Most existing studies consider incentives as reasons for retiring or reduced working hours. However, Osberg stressed that it is often impossible for older people to work. Job availability is an important factor in retirement and labour supply decisions. His empirical analysis shows that restrictions in the labour market have a significant effect on retirement decisions. Singh and Das (2015) also used the Heckman model to analyse labour among India's older population. They looked at wage earners' participation in the labour market in step 1, and analysed the number of working days per week as a dependent variable in step 2 . Their analysis was done by dividing the two time-series into urban and rural areas. They found that there was high probability of older people and the poor being engaged in wage labour.

Among existing studies on Korea, the Korea Institute of Public Finance's (KERI) report (Won et al. 2008) on the supply of labour among older people is limited because it uses crosssectional data to conduct an empirical analysis with the Heckman model. A noteworthy finding of the report is that labour supply elasticity for wages had a negative effect. This can be interpreted to mean that the income effect on leisure greatly outweighed the substitution effect for the older population in Korea. Park and Cho (2016) analysed the wage determinants of graduates from specialized high schools. Although theirs is not a study of the older population, it is methodologically the most similar to this study as they also use the Heckman sample selection model using panel data.

\section{DATA}

\subsection{Sample}

This study uses data from the Korea Longitude Study of Ageing (KLOSA). The data was collected by the Korea Employment Information Service with the purpose of providing basic data on ageing. The sample was inspected for general residence among people aged 45 years and older. The KLOSA surveyed various variables related to ageing including collecting information about economic conditions such as assets, income, pension and insurance. In addition, it also collected information about background and participation in the labour market; demographic 
characteristics of individuals, including physical and mental health; as well as residential areas and social relationships. It also includes information related to labour supply.

The KLOSA survey covered 10,000 participants. However, one problem with the data is that there are too many missing values for particular variables. We used panel data from the second survey (2008) to the sixth survey (2016), using a total of five biennial surveys, for our study. The 2006 data was excluded because of matching issues between the first survey and the data from the other rounds. The KLOSA is a survey of individuals over 45 years, but our study targets middle- and high-aged people over 55 years. In Korea, many companies have the mid-50s as the retirement age, which means that on average employed people retire around 55 years (Lee Bang 2009). We used a total of 30,398 observations in our analysis.

\subsection{Variables}

The data includes three different but sequentially interdependent variables for estimation. The dependent variable for the first stage of the (Probit) model dataset is a binary variable that indicates whether or not an individual is participating in the labour market. The dependent variables for the second stage of the Heckman two-step sample selection model are labour income and working days. Labour income is composed of annual income, combined with income from wages, self-employment and farming and fishing. The average was approximately 18.83 million won. Labour income variables were transformed to logarithmic form prior to their use in the estimation. Labour working days refer to the number of days of work per week. Table 1 provides definitions and summary statistics of the variables.

The independent variables include variables that represent the demographic characteristics of the individual and their labour market behaviour. Table 1 shows that the individual explanatory variables include age, age square, sex, marital status, education level and residential area. Among the variables related to gender, marital status, health, BMI (Body Mass Index) and health-related variables (drinking or exercising regularly) are expressed as dummy variables. Individual health is considered an important factor in taking decisions about labour participation (Behrman 1999; Currie - Madrian 1999). BMI is a representative index of an individual's anthropometrics. The variable in relation to obesity consists of four categories. Ju et al. (2017) found that it is not bad for health if older people are classified as overweight but not obese. As a result, we constructed a dummy variable by combining obesity and low weight defined as bad, and normal and overweight as good.

Table 2 provides basic information about age cohorts and their education levels. The dataset consists of people who are 55-107 years old. It shows that the proportion of labour participation decreases with age. The education level is composed of primary school (educ1), intermediate school (educ2), high school (educ3) and university (educ4). The highest percentage is in educ1 which is about half the sample. Some of the health-related variables include subjective health conditions; the BMI dummy variable; dummy variables related to health behaviour; and Center for Epidemiological Studies-Depression (CESD), which is an index for mental health conditions. Investments in ageing health improves with general economic and social conditions. This can be a viable instrument for reducing the burden of the ageing population (Heshmati 2018). Finally, there is a variable on attending gatherings, that can affect happiness or health through social relations. This variable is a health indicator in terms of Salutogenic health through the number of times one meets someone closely related (Yeo - Heshmati 2014). 
Table 1. Summary statistics of the variables (2008-2016)

\begin{tabular}{|c|c|c|c|c|c|}
\hline Variable & Definition & Mean & Std. Dev. & Min & Max \\
\hline \multicolumn{6}{|c|}{ Dependent variables: } \\
\hline work_d & $\begin{array}{l}\text { Dummy for work } \\
\text { [in work }=1 \text {, otherwise } 0 \text { ] }\end{array}$ & 0.316 & 0.465 & 0 & 1 \\
\hline Inlabourinco & Log sum of labour income & 7.164 & 0.930 & 0 & 11.002 \\
\hline whour or wday & Weekly working hours or days & 5.323 & 1.263 & 1 & 7 \\
\hline \multicolumn{6}{|c|}{ independent variables: } \\
\hline gender_d & $\begin{array}{l}\text { Dummy for gender } \\
\qquad[\text { male }=1, \text { female }=0]\end{array}$ & 0.448 & 0.497 & 0 & 1 \\
\hline mari_d & $\begin{array}{l}\text { Dummy for marriage } \\
\qquad[\text { married }=1, \text { otherwise } 0]\end{array}$ & 0.779 & 0.415 & 0 & 1 \\
\hline Educ & $\begin{array}{l}\text { Level of education [elementary or below } \\
\quad=1 \text {, middle }=2 \text {, high }=3 \\
\text { university }=4 \text { ] }\end{array}$ & 1.902 & 1.043 & 1 & 4 \\
\hline Region & $\begin{array}{l}\text { Province of residence } \\
\quad \text { [large city }=1 \text {, small city }=2, \\
\text { town }=3]\end{array}$ & 1.822 & 0.807 & 1 & 3 \\
\hline Age & Age & 69.152 & 9.221 & 55 & 107.000 \\
\hline age2 & Age squared & & & & \\
\hline health_s & $\begin{array}{l}\text { Subjective health status, ranging between } \\
0 \text { and } 100 \text { (bad good), then logged }\end{array}$ & 3.124 & 0.900 & 1 & 5 \\
\hline bmi_d & Dummy for BMI [good $=1$, bad $=0$ ] & 0.715 & 0.451 & 0 & 1 \\
\hline Cesd & $\begin{array}{l}\text { Measurement of mental health (cesd-d10) } \\
\text { ranging between } 1 \text { and } 10 \text { (good } \sim \text { bad) }\end{array}$ & 3.608 & 2.959 & 0 & 10 \\
\hline alcohol_d & $\begin{array}{l}\text { Dummy for drinking [drinks alcohol } \\
\text { regularly }=1 \text {, otherwise } 0 \text { ] }\end{array}$ & 0.322 & 0.467 & 0 & 1 \\
\hline exer_d & $\begin{array}{l}\text { Dummy for exercise } \\
\quad \text { [exercises regularly }=1 \text {, otherwise } 0]\end{array}$ & 0.344 & 0.475 & 0 & 1 \\
\hline gath_d & $\begin{array}{l}\text { Dummy for attending gatherings [at least } \\
\text { once a month }=1 \text {, otherwise }=0 \text { ] }\end{array}$ & 0.634 & 0.481 & 0 & 1 \\
\hline Lntransf & Log private transfer & 9.902 & 0.103 & 0 & 10.433 \\
\hline pen_d & $\begin{array}{l}\text { Dummy for public pension } \\
\quad \text { [pensioner }=1,0 \text { otherwise] }\end{array}$ & 0.199 & 0.400 & 0 & 1 \\
\hline worktype_d & $\begin{array}{l}\text { Dummy for work type } \\
\quad[\text { white collar }=1 \text {, blue collar }=0 \text { ] }\end{array}$ & 0.353 & 0.478 & 0 & 1 \\
\hline
\end{tabular}


Table 1. Continued

\begin{tabular}{|l|l|c|c|c|c|}
\hline Variable & \multicolumn{1}{|c|}{ Definition } & Mean & Std. Dev. & Min & Max \\
\hline empl_d & $\begin{array}{l}\text { Dummy for wage work } \\
\text { [wage worker = 1, self-employed = 0] }\end{array}$ & 0.479 & 0.500 & 0 & 1 \\
\hline Lninco & $\begin{array}{l}\text { Log sum of private total income except } \\
\text { labour income }\end{array}$ & 5.274 & 1.878 & 0 & 10.611 \\
\hline Lnpnet & Log personal net wealth & 10.865 & 0.316 & & 13.403 \\
\hline
\end{tabular}

Source: authors.

Labour behaviour related variables include personal transfers; public pensions; types of work; wages or self-employed income; personal total income; and personal assets. First, aggregate private transfer income is included in logarithmic form. The ratio of the givers to the takers is approximately 9:1. The public pension variable is a dummy variable and includes the national pension and special employment pension. Public and private pensions have a significant impact on older people's labour market participation (Mitchell - Fields 1984). Starting in 1999, Korea extended the beneficiaries of its national pension plan to the entire population, but the amount

Table 2. Mean dependent variables by age cohorts and education levels

\begin{tabular}{|l|c|c|c|}
\hline Group & Proportion & Work & Labour income \\
\hline $55-59$ & 18.21 & 61.77 & 2613.61 \\
\hline $60-64$ & 17.60 & 47.39 & 1936.13 \\
\hline $65-69$ & 17.58 & 32.90 & 1507.32 \\
\hline $70-74$ & 17.54 & 22.73 & 1123.44 \\
\hline $75-79$ & 14.23 & 14.35 & 853.02 \\
\hline $80-89$ & 13.18 & 5.98 & 813.53 \\
\hline $90-$ & 1.68 & 2.00 & 488.00 \\
\hline Sum & 100.00 & 31.55 & 1883.53 \\
\hline educ1 & 50.99 & 22.67 & 1074.02 \\
\hline educ2 & 16.56 & 37.38 & 1633.34 \\
\hline educ3 & 23.67 & 43.94 & 2319.60 \\
\hline educ4 & 8.77 & 40.65 & 3739.72 \\
\hline Sum & 100.00 & 31.55 & 1883.53 \\
\hline
\end{tabular}

Source: authors. 
of benefits is not significant. Many studies have shown that pension systems have a negative impact on beneficiaries' work supply before retirement (Choi 2006; Lee - Choi 2007).

The 'work type' variables were separated into white collar and blue collar workers by correcting the raw data and converting it into dummy variables. The personal total income variable is the logarithm of the total income of individuals. The personal net asset variable consists of individual gross assets minus individual gross liabilities. As with transfer income, the variables for personal total income and personal net assets are transformed into logarithmic form.

\section{MODEL SPECIFICATION AND ESTIMATION}

\subsection{Labour supply model}

A function that determines whether to participate in the labour market is made up of wages in the labour market or labour income and demand for personal leisure. Because an individual's utility from leisure is a non-measurable factor, Becker (1964) and Mincer (1974) analysed labour supply using a wage decision model:

$$
\begin{aligned}
& \left.\begin{array}{l}
W=\beta_{1}+\beta_{2}^{\prime} X_{1}+\varepsilon_{1} \\
H=\beta_{3}+\beta_{4}^{\prime} X_{2}+\varepsilon_{2}
\end{array}\right] \text { if } W>W_{r}, H>0 \\
& H=0 \text { otherwise }
\end{aligned}
$$

If the wage $(W)$ received in the market exceeds an individual's shadow wage, or reservation wage $\left(W_{r}\right)$, the individual participates in the labour market. An individual's working hours are determined at the point where the wages offered are equal to the reservation wage. However, in this case, the observations used for estimating the expected wages are only those that are being paid. As a result, the problem of selectivity bias occurs because $\mathrm{E}\left(\varepsilon_{1} / H>0\right)$ is not zero.

\subsection{The Heckman sample selection model}

If individuals who do not participate in the labour market are excluded from the sample, the sample is not random and neither does it represent the older population. Therefore, the results of an analysis of only working individuals cannot be used to infer about older population. The study of these sample choices was initiated by Tobin (1958) in econometrics. Later, Amemiya (1984) solved the problem leading to a part of the dependent variable being censored. In case of non-participation in labour market, the wage is deemed to be zero. Under this model, the effect of participation in the labour market and the size of the wage are estimated simultaneously as:

$$
\begin{gathered}
y_{i t}^{*}=x_{i t}^{\prime} \beta+\varepsilon_{i t} \\
\varepsilon_{i t} \sim N\left(0, \sigma^{2}\right), i=1,2, \ldots, n \\
y_{i t}=\left\{\begin{array}{l}
y_{i t}^{*}, \text { if } y_{i t}^{*}>0 \\
0, \text { if } y_{i t}^{*} \leq 0
\end{array}\right.
\end{gathered}
$$

where $y_{i t}$ is observed wages, $y_{i t}^{*}$ refers to latent wages, $x_{i t}$ is a vector of exogenous variables or determinants of wages, $\varepsilon_{i t}$ are random error terms and $\beta$ is the vector of unknown parameters 
to be estimated. The observed wages $y_{i t}$ have a value for latent wage $y_{i t}^{*}$ when $y_{i t}^{*}>0$ otherwise $y_{i t}=0$. In Equation (2), the expected value of the latent dependent variable $y_{i t}^{*}$ is:

$$
E\left(y_{i t}^{*} / y_{i t}^{*}>0\right)=x_{i t}^{\prime} \beta+\sigma\left(\phi_{i t} / \Phi_{i t}\right)
$$

where $\phi_{i}$ is the standard normal density function and $\Phi_{i t}$ the standard normal cumulated function for $x_{i t}^{\prime} \beta / \sigma$. In the Tobit model, these expected values are obtained by a way that maximizes the maximum likelihood value.

5.2.1. Labour participation. Heckman $(1976 ; 1977)$ analysed the problem with the assumption that the effects of the variables on labour market participation and labour income are not the same. Therefore, he estimated the model in two steps:

$$
\begin{aligned}
& p_{i t}^{*}=w_{i t}^{\prime} \gamma+u_{i t}, p_{i}=\left\{\begin{array}{l}
1, \text { if } p_{i t}^{*}>0 \\
0, \text { if } p_{i t}^{*} \leq 0
\end{array}\right. \\
& y_{i t}^{*}=x_{i t}^{\prime} \beta+\varepsilon_{i t}, y_{i t}=\left\{\begin{array}{l}
y_{i t}^{*}, \text { if } p_{i t}^{*}>0 \\
0, \text { if } p_{i t}^{*} \leq 0
\end{array}\right.
\end{aligned}
$$

In the sample selection Model (4), the sample is chosen by a third variable, $p_{i t}^{*}$, not $y_{i t}^{*} \cdot p_{i t}^{*}$, which is based on the choice of samples, is a latent variable not directly observed. $p_{i t}$ is a variable that is observed according to latent variable. $\beta$ and $\gamma$ are vectors of the parameters to be estimated, and $\varepsilon_{i t}$ and $u_{i t}$ are error terms. $x_{i t}$ and $w_{i t}$, refer to vectors of the explanatory variable related to the size of wages and employment status, respectively. The explanatory variable's vectors consist of independent individual characteristics and labour market related variables.

In our study, $p_{i t}^{*}$ is a potential variable of the willingness to participate in the labour market, and unless there are other costs involved in the labour market, $p_{i t}^{*}$ comprises of the difference between labour income and reservation wages. $y_{i t}^{*}$ is a potential variable that indicates the size of the wage, $p_{i t}$ is an observable variable for the labour market, and if $p_{i t}^{*} \neq 0$, then it will be 1 ; otherwise, it will be 0 (Breen 1996). The decision to participate in the labour market and the determinants of wage are determined simultaneously. In this case, there is a correlation between the error terms. Because the tendency to work is decided by the difference between real labour income and reservation wages, the error terms affecting wages also affect the decision to work:

$$
\begin{gathered}
\mathrm{E}\left(y_{i t} / p_{i t}^{*}>0\right)=x_{i t}^{\prime} \beta+E\left(\varepsilon_{i t} / u_{i t}>-w_{i t}^{\prime} \gamma\right)=x_{i t}^{\prime} \beta+\rho \sigma \frac{\phi\left(-w_{i t}^{\prime} \gamma\right)}{1-\Phi\left(-w_{i t}^{\prime} \gamma\right)}=x_{i t}^{\prime} \beta+\beta_{\lambda} \lambda\left(-w_{i t}^{\prime} \gamma\right) \\
y_{i t} / p_{i t}^{*}=E\left(y_{i t} / p_{i t}^{*}>0\right)+\nu_{i t}=x_{i t}^{\prime} \beta+\beta_{\lambda} \lambda\left(-w_{i t}^{\prime} \gamma\right)+\nu_{i t}
\end{gathered}
$$

Where $\phi\left(-w_{i t}^{\prime} \gamma\right)$ indicates a probability density function of a standard normal distribution, and $\Phi\left(-w_{i t}^{\prime} \gamma\right)$ shows a standard normal distribution function. $\lambda\left(-w_{i t}^{\prime} \gamma\right)$ is the inverse mills ratio, that is, the hazard rate that each observation is excluded from the sample (Tuma 1982). The inverse mills ratio is a new explanatory variable in the second-step and $\rho \sigma$ is the regression coefficient instead of $\beta_{\lambda}$.

The Heckman model, which estimates $\tilde{\gamma}$, is based on all samples in the first stage using a Probit model, and then $w_{i t}^{\prime} \tilde{\gamma}$ were obtained used in the second step, to obtain $\beta$ and the 
consistent estimator of $\beta_{\lambda}$ through least square regression. If $\rho \neq 0$, then there is a bias equalling $\rho \sigma\left(-w_{i t}^{\prime} \gamma\right)$.

5.2.2. Labour earnings model. In the Heckman model, the second step is estimating the potential differential variable in the full sample through output Equation (7). Our study estimates labour earnings, including for self-employed, and labour days per week. First, for using panel data, the model to be used needs to be determined. The panel fixed effects or random effects model is used to estimate the model. The difference between the two models is whether the error term representing the unobservable individual characteristics is considered to be a parameter to be estimated or just a random effect. A fixed effects model is useful when there is correlation between the explanatory variable and the unobservable individual effects. When using a fixed effects model, the method addresses endogeneity problems and provides consistent and unbiased estimates.

The random effects model treats the unobservable individual effects as error terms which are independent from the explanatory variables, allowing the estimation of time-invariant variables, but not addressing the endogeneity problems (Lee 2001). In other words, the choice between the two models depends on the existence of a correlation between the independent variables and unobservable individual effects $\left(\operatorname{cov}\left(x_{i t}, u_{i}\right)=0\right)$. The Hausman test (Hausman 1978) is a general method for the selection between these two models:

$$
\begin{aligned}
& H_{0}=\operatorname{cov}\left(x_{i t}, u_{i}\right)=0 \\
& H_{1}=\operatorname{cov}\left(x_{i t}, u_{i}\right) \neq 0
\end{aligned}
$$

The random effects model is preferred if the hypothesis of the Hausman test is accepted, or a fixed-effects model is preferred if the null hypothesis is rejected. The Hausman test of the models for labour income and labour supply analysed in this study, showed that the model for labour income needs to be estimated with a fixed effects model.

In this study, individual explanatory variables such as gender, marital status, education level and residential region are time-invariant variables. The fixed effects model, including the timeinvariant variable, can be estimated using the Hausman and Taylor (1981) approach. Each of these models uses instrumental variables to resolve endogeneity. First, exogenous variables that are unrelated to $u_{i}$ are themselves instrumental variables. The time-variant endogenous variables, $x_{2 i t}$ have $\left(x_{2 i t}-\bar{x}_{2 i}\right)$ as the instrumental variables and the time-invariant endogenous variables $z_{2 i}$ take $\bar{x}_{1 i}$ as the instrumental variables (Hausman - Taylor 1981):

$$
y_{i t}=x_{1 i t}^{\prime} \beta_{1}+x_{2 i t}^{\prime} \beta_{2}+z_{1 i}^{\prime} \beta_{3}+z_{2 i}^{\prime} \beta_{4}+u_{i}+\varepsilon_{i t}
$$

where $x_{1 i t}$ and $x_{2 i t}$ are time-variant, not correlated with the unobservable individual effects $u_{i} ; z_{1 i}$ and $z_{2 i}$ are time-invariant, not correlated with $u_{i}$, and $\varepsilon_{i t}$ is random error term.

In the labour income model the time-variant exogenous variables include age and public pension, and the time-variant endogenous variables are residential region, health-related variables, working type, dummy of self-employed, private transfer income, labour time and the inverse mills ratio, which was previously obtained from the estimated Probit model. Finally, there are gender, marital status and education status among the time-invariant exogenous variables. The fixed effects (FE) and random effects (RE) of the labour earning and labour day models and their difference is presented in Table 3. 
Table 3. Results of Hausman test (FE = Fixed Effects, RE $=$ Random Effects)

\begin{tabular}{|l|c|c|c|l|c|c|c|}
\hline \multicolumn{2}{|l}{ Labour earnings model } & \multicolumn{1}{|c|}{ Labour days model } \\
\hline & RE & FE & Difference & & \multicolumn{5}{c|}{ RE } & FE & Difference \\
\hline region2 & -0.199 & -0.029 & -0.170 & region2 & 0.284 & -0.012 & 0.297 \\
\hline region3 & -0.088 & -0.389 & -0.049 & region3 & 0.117 & 0.050 & 0.066 \\
\hline age & 0.068 & 0.381 & 0.030 & age & 0.364 & -0.123 & 0.487 \\
\hline age2 & -0.001 & 0.001 & -0.000 & age2 & 0.001 & 0.001 & -0.000 \\
\hline health_su & 0.017 & -0.418 & 0.058 & health_su & 0.008 & 0.001 & 0.007 \\
\hline bmi_d & 0.024 & 0.235 & 0.001 & bmi_d & 0.001 & -0.001 & 0.000 \\
\hline cesd & -0.002 & -0.004 & 0.001 & cesd & -0.011 & -0.001 & -0.010 \\
\hline gath_d & -0.034 & 0.032 & -0.002 & alcohol_d & 0.049 & 0.003 & 0.045 \\
\hline worktype_d & 0.055 & 0.250 & -0.195 & exer_d & -0.040 & -0.105 & 0.064 \\
\hline emp_d & -0.274 & -0.095 & -0.178 & gath_d & -0.066 & -0.032 & -0.034 \\
\hline pen_d & 0.040 & 0.132 & -0.092 & worktype_d & 0.341 & 0.167 & 0.174 \\
\hline transf_d & -0.029 & -0.060 & 0.031 & emp_d & -0.566 & -0.676 & 0.110 \\
\hline Intransf & 0.288 & 0.010 & 0.277 & pen_d & -0.039 & -0.017 & -0.022 \\
\hline days & 0.071 & 0.073 & -0.002 & transf_d & 0.073 & 0.076 & -0.003 \\
\hline Inhour & 0.074 & 0.187 & -0.113 & Inwealth & -0.036 & -0.072 & 0.036 \\
\hline invMR & -0.217 & -0.002 & -0.019 & Inearned & 0.231 & 0.298 & -0.067 \\
\hline & & & & invMR & -0.121 & -0.121 & -0.000 \\
\hline chi2(19) $=143.56$ & & & chi2(20) $=36.17$ & & \\
\hline Prob > chi2 $=0.000$ & & & & & & \\
\hline & & & & & & & \\
\hline
\end{tabular}

Source: authors.

5.2.3. Labour working day model. The labour supply model has the working days per week as the dependent variable. However, this variable is count data which is an integer, so the generalized linear model cannot be applied. Typical generalized linear models include the Poisson regression model and the negative binomial regression model (Cameron - Trivedy 1986). However, there is a restriction that the Poisson regression model should have the same conditional distribution as the conditional mean. Thus, there are disadvantages of lower efficiency when the mean and the variance of the coefficients increase (Cox 1983; Gurmu 1991). Negative binomial distribution is a more generalized Poisson distribution, defined as a variance function that allows for heteroscedasticity and can be a means of 
solving the problem of the Poisson distribution in that the means and variances differ significantly.

\section{EMPIRICAL RESULTS}

Table 4 shows the estimation results from the model of participation of older people in the labour market in Korea. The table reports the first step in the Heckman sample selection model using 12,920 observations in the Probit model of 5,524 individuals.

Table 4. Labour participation model estimation results

\begin{tabular}{|l|c|c|c|}
\hline Variable & Coefficient & Std. Error & P > |z| \\
\hline gender_d & $3.014^{* * *}$ & 0.159 & 0.000 \\
\hline mari_d & $-0.980^{* * *}$ & 0.150 & 0.000 \\
\hline age & $0.283^{* * *}$ & 0.082 & 0.001 \\
\hline age2 & $-0.003^{* * *}$ & 0.001 & 0.000 \\
\hline educ2 & $-0.360^{* *}$ & 0.154 & 0.020 \\
\hline educ3 & $-0.447^{* * *}$ & 0.151 & 0.003 \\
\hline educ4 & $-0.561^{* *}$ & 0.220 & 0.011 \\
\hline region2 & $0.226^{*}$ & 0.121 & 0.062 \\
\hline region3 & $1.184^{* * *}$ & 0.140 & 0.000 \\
\hline health_s & $-0.492^{* * *}$ & 0.052 & 0.000 \\
\hline bmi_d & 0.103 & 0.930 & 0.275 \\
\hline cesd & $-0.092^{* * *}$ & 0.014 & 0.000 \\
\hline exer_d & $-0.935^{* * *}$ & 0.085 & 0.000 \\
\hline alcohol_d & $0.794^{* * *}$ & 0.104 & 0.000 \\
\hline pen_d & $2.144^{* * *}$ & 0.120 & 0.000 \\
\hline transf_d & $-0.596^{* * *}$ & 0.122 & 0.000 \\
\hline Ininco & $-0.504^{* * *}$ & 0.028 & 0.000 \\
\hline Inwealth & $0.296^{*}$ & 0.161 & 0.067 \\
\hline Observations & 12,920 & & \\
\hline No. of individuals & 5,524 & & \\
\hline Log likelihood & -3414.2348 & & \\
\hline & & & \\
\hline & & & \\
\hline
\end{tabular}

Notes: Standard errors in parentheses; ${ }^{* * *}$ indicates $P<0.01,{ }^{* *} P<0.05, * P<0.1$.

Source: authors. 
With a few exceptions (BMI and wealth), all variables are statistically significant at less than $5 \%$ level of significance. Gender (male $=1$ ) was found to be statistically significant in the labour participation model. This can be explained with the traditional role of the head of the household being played by men. Unmarried elderlies are more likely to participate in the labour market than married ones. Given that there are about six times more older people who are receiving private transfers, the effect of being married can be separated from the effects of children's support to ageing parents. The age variable has a positive effect on labour market participation, while the square of age is negatively related. This suggests that the relationship is non-linear and age increases labour market participation but at a decreasing rate. Higher education levels reduce labour market participation among older people at an increasing rate.

The residential area of small towns is significant and has larger impact than large cities. This is similar to the results of another study (Bang et al. 2005) which suggested that the retirement age for older people in the agricultural and fisheries industries started at a later age. Subjective health conditions and the CESD index that represent mental health have negative coefficients that can be interpreted in relation to poverty among older people. According to a preliminary study (Kang 2015), the labour market participation of older Koreans is greatly affected by their poverty conditions. Continuing to work despite their low reservation wages, older people have to remain in labour market to make a living.

In addition, because health conditions are more likely to be poor among the economically poor, this can explain why the coefficients of the health-related variables are negative. Among health-related variables, a positive variable is whether a person drinks alcohol frequently or not. This can also be explained in relation to the poverty of older people. For labour-related variables, both private transfers and individual gross assets produced statistically significant and negative values. Finally, public pension came up with an unexpected positive coefficient. This contradicts the results of existing studies in other countries. One explanation is that a high level of wages while working leads to high living standards and expenditure for housing; cars and other durable consumption items; and social activities which can be maintained only if one continues working after the retirement age.

Table 5 reports the results of the estimation of the labour income model or the second stage of the Heckman's two-stage method. The number of individuals used are 2,199, and the total number of observations is 4,200. The estimation methods include fixed effects, random effects and the Hausman-Taylor (HT) methods. Overall, the results of the analysis show that the RE model has slightly more significant values than the HT model. The Hausman test rejected the RE model. Thus, while the fixed effects model is consistent and unbiased, labour income was analysed through the Hausman-Taylor model and compared with the random effects model due to the presence of time-invariant variables in the model. This model assumes some part of the sample as random while another part as fixed. This approach accounts for both heterogeneity and endogeneity, and as such is immune to misspecifications and loss of efficiency.

The age variable was marked by a positive income effect. In the case of the dummy variable for wage workers, there are statistically significant negative values indicating that the selfemployed had greater labour income than wage workers. Among older people, self-employment was preferred, and the value of the variable's coefficient in the model for working days does not have a statistically significant negative sign. This can be interpreted as preferring self-employment is affected by the size of the income rather than by differences in labour intensity. The 
Table 5. Labour income model of older people's labour market participation

\begin{tabular}{|c|c|c|c|c|c|c|}
\hline \multirow[b]{2}{*}{ Variable } & \multicolumn{2}{|c|}{ Model1 (Hausman-Taylor) } & \multicolumn{2}{|c|}{ Model2 (RE GLS) } & \multicolumn{2}{|c|}{ Model3 (FE within) } \\
\hline & Coef. & Std. Err. & Coef. & Std. Err. & Coef. & Std. Err. \\
\hline age & $0.105 * * *$ & 0.034 & 0.038 & 0.025 & 0.069 & 0.296 \\
\hline age2 & $-0.001 * * *$ & 0.001 & $-0.001 * * *$ & 0.000 & $-0.001 * * *$ & 0.000 \\
\hline pen_d & $0.132 * * *$ & 0.026 & $0.133^{* * *}$ & 0.024 & 0.040 & 0.033 \\
\hline region2 & $-0.278^{*}$ & 0.157 & -0.029 & 0.030 & -0.200 & 0.169 \\
\hline region3 & -0.233 & 0.181 & -0.039 & 0.036 & -0.089 & 0.199 \\
\hline health_s & 0.019 & 0.017 & $-0.042 * * *$ & 0.014 & 0.017 & 0.018 \\
\hline bmi_d & 0.028 & 0.037 & 0.024 & 0.025 & 0.024 & 0.039 \\
\hline cesd & -0.004 & 0.004 & -0.004 & 0.004 & -0.003 & 0.005 \\
\hline gath_d & -0.035 & 0.023 & $-0.033^{*}$ & 0.019 & -0.034 & 0.024 \\
\hline worktype_d & 0.100 & 0.061 & $0.250 * * *$ & 0.028 & 0.055 & 0.065 \\
\hline emp_d & $-0.221 * * *$ & 0.061 & $-0.096 * * *$ & 0.027 & $-0.274 * * *$ & 0.067 \\
\hline transf_d & -0.034 & 0.027 & $-0.060 * * *$ & 0.023 & -0.029 & 0.029 \\
\hline Intransf & 0.316 & 0.205 & 0.010 & 0.091 & 0.288 & 0.215 \\
\hline wday & $0.072 * * *$ & 0.011 & $0.074 * * *$ & 0.010 & $0.071 * * *$ & 0.012 \\
\hline whour & $0.078 * * *$ & 0.024 & $0.188 * * *$ & 0.021 & $0.074 * * *$ & 0.026 \\
\hline gender_d & $0.470 * * *$ & 0.048 & $0.529 * * *$ & 0.037 & & \\
\hline mari_d & $0.131 * *$ & 0.052 & $0.086^{*}$ & 0.086 & & \\
\hline educ2 & $0.164 * * *$ & 0.052 & $0.124 * * *$ & 0.041 & & \\
\hline educ3 & $0.254 * * *$ & 0.057 & $0.190 * * *$ & 0.039 & & \\
\hline educ4 & $0.696 * * *$ & 0.080 & $0.562 * * *$ & 0.051 & & \\
\hline invMR & -0.024 & 0.026 & -0.002 & 0.018 & -0.022 & 0.028 \\
\hline Observations & 4,200 & & 4,200 & & 4,200 & \\
\hline No. of pid & 2,199 & & 2,199 & & 2,199 & \\
\hline Prob > chi2 & 0.000 & & 0.000 & Prob $>F$ & 0.000 & \\
\hline
\end{tabular}

Notes: Standard errors in parentheses; ${ }^{* * *}$ indicates $P<0.01,{ }^{* *} P<0.05, * P<0.1$.

Source: authors.

gender variable indicates that men earn higher incomes than women. This result is commonly known. Education levels also show an increasing effect on labour incomes.

Variables for public pension have positive coefficients and are statistically significant. In Korea, the National Pension Service has not been operating for long time. Therefore, the public 
Table 6. Labour day model of older people's labour market participation

\begin{tabular}{|c|c|c|c|c|c|c|}
\hline \multirow[b]{2}{*}{ Variable } & \multicolumn{2}{|c|}{ Model1 (Negative binomial) } & \multicolumn{2}{|c|}{ Model2 (Hausman-Taylor) } & \multicolumn{2}{|c|}{ Model3 (FE within) } \\
\hline & Coef. & Std. Err. & Coef. & Std. Err. & Coef. & Std. Err. \\
\hline age & $-0.025^{*}$ & 0.014 & $-0.100 * *$ & 0.043 & 0.263 & 0.525 \\
\hline age2 & $0.001 *$ & 0.000 & $0.001 * *$ & 0.000 & 0.001 & 0.000 \\
\hline pen_d & -0.000 & 0.014 & -0.031 & 0.034 & -0.031 & 0.047 \\
\hline transf_d & 0.007 & 0.014 & $0.073 * *$ & 0.029 & $0.078 * *$ & 0.039 \\
\hline Inwealth & -0.008 & 0.022 & -0.048 & 0.066 & -0.055 & 0.092 \\
\hline region2 & -0.001 & 0.014 & $0.502 * *$ & 0.207 & $0.488^{*}$ & 0.275 \\
\hline region3 & 0.021 & 0.016 & 0.247 & 0.228 & 0.229 & 0.303 \\
\hline health_s & -0.004 & 0.009 & 0.002 & 0.019 & 0.002 & 0.026 \\
\hline bmi_d & -0.003 & 0.014 & 0.012 & 0.043 & 0.012 & 0.057 \\
\hline cesd & 0.001 & 0.002 & $-0.010^{*}$ & 0.005 & -0.010 & 0.007 \\
\hline alcohol_d & 0.002 & 0.013 & 0.007 & 0.055 & 0.002 & 0.073 \\
\hline exer_d & -0.013 & 0.014 & -0.039 & 0.030 & -0.038 & 0.040 \\
\hline gath_d & 0.004 & 0.013 & $-0.067^{* *}$ & 0.026 & $-0.067 *$ & 0.035 \\
\hline worktype_d & 0.021 & 0.014 & $0.257^{* * *}$ & 0.070 & $0.257 * * *$ & 0.092 \\
\hline emp_d & $-0.104 * * *$ & 0.013 & $-0.540 * * *$ & 0.073 & $-0.538 * * *$ & 0.097 \\
\hline whour & $0.225^{* * *}$ & 0.014 & $0.760 * * *$ & 0.027 & $0.760 * * *$ & 0.036 \\
\hline labourinco & $0.027 * * *$ & 0.009 & $0.140 * * *$ & 0.024 & $0.140 * * *$ & 0.032 \\
\hline invMR & -0.013 & 0.010 & $-0.095^{* * *}$ & 0.029 & $-0.095^{* *}$ & 0.039 \\
\hline gender_d & $-0.062 * * *$ & 0.019 & $-0.310 * * *$ & 0.111 & & . \\
\hline mari_d & 0.004 & 0.020 & 0.034 & 0.146 & & . \\
\hline educ2 & -0.023 & 0.018 & -0.108 & 0.140 & & . \\
\hline educ3 & -0.007 & 0.017 & -0.062 & 0.134 & & . \\
\hline educ4 & -0.010 & 0.025 & -0.153 & 0.176 & & . \\
\hline Observations & 5,425 & & 5,425 & & 5,425 & \\
\hline No. of pid & 2,539 & & 2,539 & & 2,539 & \\
\hline Prob>chi2 & 0.0000 & & 0.0000 & Prob $>F$ & 0.0000 & \\
\hline
\end{tabular}

Notes: Standard errors in parentheses; ${ }^{* * *}$ indicates $P<0.01,{ }^{* *} P<0.05$, and $* P<0.1$.

Source: authors

national pension fund has a strong role as a means of savings for retirement. On the other hand, in a country where social security has been in operation for a longer time, public pension is a social safety net of universal welfare. However, there is a difference between Korea and other 
countries in the impact that public pension has on the labour supply of older people. In addition, in Korea, the main reason for not joining or being eligible for the National Pension Service is because it provides little or no income coverage.

Table 6 shows the estimation results of work days per week using count data models, Hausman-Taylor and within estimation methods. In the case of the weekly labour day model, the Hausman test's results do not reject the null hypothesis. However, a typical regression analysis is not appropriate for the model since the dependent variables are in a count data form. For count data, the Poisson regression model and the negative binomial regression (NB model) can be used for the analysis. In this study, a model of labour days per week was analysed using negative binomial regression. The analysis used 2,539 individuals' data and the number of observations was 5,428 .

The estimation result show that statistically significant effects are related to the dummy variable for wage workers, labour time, labour income and gender. As with the labour income model, the inverse mills ratio is not significant, which makes the sample selection model less feasible. First, the negative coefficient of gender is in contrast to the previous model. This means that women, especially older people, are more likely to engage in low-skilled, low-paying jobs than men. The wage worker dummy variable also has a negative coefficient, which is the same as the coefficients in the labour income model as self-employed people may work less and earn more than wage workers.

\section{CONCLUSION}

This study used panel data from the Korean Longitudinal Study of Ageing (KLOSA) for an empirical analysis of the older population's work. It used the Heckman sample selection model to analyse older people's labour supply, focussing on their labour participation, extensive margins and labour supply and intensive margins. The effects of pension were noticeable because this indicates that research on similar cases in other countries has produced conflicting results. The results of our analysis are summarized as follows. First, older men are more likely to participate in the labour market than older women, and they earn more money, but for a given income level they have less work hours than women. Second, the higher the level of education, the less likely older people are in the need of participating in the labour market. Third, in the case of public pension, it can be seen that older people, who are subscribers and who are now receiving pension, are more likely to work after retirement and they will also get paid more.

This analysis shows that the socially disadvantaged older population is more likely to participate in the labour market, but these people receive lower incomes and undertake longer working hours. Hence, to eliminate this imbalance between classes, the state must protect the vulnerable through the social safety net and public pension for older people. However, the public pension fund in Korea does not play a role in protecting the vulnerable. The statistically significant positive coefficient for public pension may be due to the possibility that the National Pension Service's subscribers are employees with relatively stable jobs. If so, the pension service as a social safety net, does not play a role in protecting the vulnerable. This can be attributed to the fact that the public pension system has not been in effect for long time.

There is a likelihood that with an inefficient public pension system, older people's life expectancy gradually increasing, and private transfers from children decreasing due to falling birth 
rates, poverty will increase among older people. To solve this problem of poverty, an increase in labour participation will be necessary for maintaining higher living standards among older population and easing the cost burden of developing a welfare system.

Policies aimed at increasing the employment rate among older people may lead to another class conflict due to the gap between the high employment rate among older population and the low youth employment rate in Korea. Also, if the number of jobs available to older people is saturated, older people may fall into another phase of competition where they work more and earn less. Hence, measures are needed for ageing, and an increase in labour participation by older people may have desirable consequences not only for older people but also for society as a whole. Therefore, at the same time as a policy aim at increasing labour among older population, the stability of such jobs have to be guaranteed. In addition, the current serious youth unemployment problem in Korea will also need to be addressed.

\section{REFERENCES}

Amemiya, T. (1984): Tobit Models: A Survey. Journal of Econometrics 24(1-2): 3-61.

Bang, B. - Shin, D. - Kim, D. - Shin, H. (2005). Ageing Population and Changing Labour Market and Labour Policies. Seoul: Korea Labour Institute.

Becker, G.S. (1964): Human Capital. New York: Columbia University.

Behrman, J.R. (1999): Labour Markets in Developing Countries. In: Ashenfelter, O. - Card, D. (eds): Handbook of Labour Economics. Amsterdam: Elsevier, pp. 2859-2939.

Breen, R. (1996): Regression Models: Censored, Sample Selected, or Truncated Data. Thousand Oaks: Sage. Cameron, A.C. - Trivedi, P.K. (1986): Econometric Models Based on Count Data. Comparisons and Applications of Some Estimators and Tests. Journal of Applied Econometrics 1(1): 29-53.

Choi, S. (2006): An Empirical Analysis of the Retirement Behavior of Double-income Households. The Journal of Labour Economy 29(1): 129-152.

Cox, D.R. (1983): Some Remarks on Overdispersion. Biometrika 70(1): 269-274.

Currie, J. - Madrian, B.C. (1999): Health, Health Insurance and the Labour Markets. In: Ashenfelter, O. Card, D. (eds): Handbook of Labour Economics. Amsterdam: Elsevier, pp. 3309-3416.

Feldstein, M. (1974): Social Security, Induced Retirement, and Aggregate Capital Accumulation. Journal of Political Economy 82(5): 905-926.

Gillion, C. (2000): The Development and Reform of Social Security Pensions: The Approach of the International Labour Office. International Social Security Review 53(1): 35-63.

Gruber, J. - Wise, D. (1997): Social Security Programs and Retirement around the World. NBER Working Paper 6134.

Gurmu, S. (1991): Tests for Detecting Overdispersion in the Positive Poisson Regression Model. Journal of Business \& Economic Statistics 9(2): 215-222.

Hausman, J.A. (1978): Specification Tests in Econometrics. Econometrica 46(6): 1251-1271.

Hausman, J.A. - Taylor, W.E. (1981): Panel Data and Unobservable Individual Effects. Econometrica 49(6): 1377-1398.

Heckman, J.J. (1976): The Common Structure of Statistical Models of Truncation, Sample Selection and Limited Dependent Variables and a Simple Estimator for such Models. Annals of Economic and Social Measurement 5(4): 475-492. 
Heckman, J.J. (1977): Sample Selection Bias as a Specification Error (with an Application to the Estimation of Labour Supply Functions). NBER Working Paper. 172.

Heshmati, A. (2018): Healthy Ageing as a Solution to the 'Ticking Time Bomb': Dealing with Ageing Population in Urban China. Sociology International Journal 2(2): 94-104.

Hinrichs, K. - Aleksandrowicz, P. (2006): Reforming European Pension Systems for Active Ageing. International Social Science Journal 58(190): 585-599.

Hurd, M.D. - Boskin, M.J. (1984): The Effect of Social Security on Retirement in the Early 1970s. The Quarterly Journal of Economics 99(4): 767-790.

Iams, H.M. (1987): Jobs of Persons Working after Receiving Retired-Worker Benefits. Social Security Bulletin 50(11): 4-19.

Jeon, S. (2010): The Effect of Lifetime Pension Benefits on Retirement Timing and the Provision of Retirement Workers. Financial Policy Issues 12(1): 3-32.

Ju, S. - Lee, J. - Kim, D. (2017): Association of Metabolic Syndrome and its Components with All-Cause and Cardiovascular Mortality in the Elderly: A Meta-Analysis of Prospective Cohort Studies. Medicine 96(45): e8491.

Kang, S. (2015): The Impact of the National Pension on the Participation of the Elderly in the Labour Market. Journal of the Institute for Policy Analysis and Evaluation 25: 165-195.

Kim, H. (2018): A Study on the Influence of the Perception of the Retirement Life on the Preparation Behavior for Elderly - Focusing on the Control Effects of the Elderly's Cognition of the Welfare System. Social Welfare in Korea 32: 53-80.

Kwon, H. - Park, C. (2017): A Study on the Relationship between the Pension and the Labour of the Elderly. Social Science Research 33(4): 1-21.

Lee, S. - Bang, H. (2009): Work on the Retirement Process of Middle and Old Workers. Social Security Research 25(3): 59-82.

Lee, S. - Choi, K. (2007): The Impact of National Pension on the Retirement Behavior of Middle and High Age People. Social Security Research 23(4): 83-103.

Lee, Y. (2001): A Study on the Linear Panel Data Model. The Korean Econometric Society 12: 105-138.

Mincer, J. (1974): Schooling, Earnings and Experience. Washington: National Bureau of Economic Research.

Mitchell, O.S. - Fields, G.S. (1984): The Economics of Retirement Behavior. Journal of Labour Economics 2(1): 84-105.

Osberg, L. (1993): Is it Retirement or Unemployment? Induced 'Retirement' and Constrained Labour Supply among Older Workers. Applied Economics 25(4): 505-519.

Pampel, F.C. - Weiss, J.A. (1983): Economic Development, Pension Policies, and the Labour Force Participation of Aged Males: A Cross-National, Longitudinal Approach. American Journal of Sociology 89(2): 350-372.

Park, K. (2000): The Social Relationship of the Elderly in Korea: Family and Community Relations. Korean Sociology 34(3): 621-647.

Park, K. (2003): The process of Leaving the Labour Market for the Aged 55 and Older; The Implications for the Tangibleization of Retirement. Labour Policy Research 3(1): 103-140.

Park, S. - Cho, J. (2016): Analysis of Wage Decision Factors that Reflect the Sample Selection Bias. The Journal of Data Information Science 27(5): 1317-1332.

Purcell, P.J. (2000): Older Workers: Employment and Retirement Trends. Monthly Labour Review 123(19).

Qiu, J. (2007): Ticking Time Bomb Faced by China’s Ageing Population. The Lancet Neurology 6(7): 582-583.

Quinn, J.F. (1999): Has the Early Retirement Trend Reversed? Boston College Working Papers in Economics 424. 
Quinn, J.F. - Kozy, M. (1996): The Role of Bridge Jobs in the Retirement Transition: Gender, Race, and Ethnicity. The Gerontologist 36(3): 363-372.

Quinn, J.F. - Burkhauser, R.V. (1994): Retirement and Labour Force Behavior of the Elderly. In: Martin, L.G. - Preston, S.H. (eds): Demography of Ageing. Washington: National Academy Press, pp. 50-101. Shin, D. - Yang, K. (2003): A Study on the Employment Policy of the Elderly in Ageing Society. Age Studies in Korea 23: 111-128.

Singh, A. - Das, U. (2015): Increasing Compulsion to Work for Wages: Old Age Labour Participation and Supply in India Over the Past Two Decades. Journal of Population Ageing 8(4): 303-326.

Song, I. - Park, M. (2012): A Comparative Analysis of Employment Determinants of the Elderly and the Semi-Elderly. Social Science Research 19(2): 7-26.

Suk, J. - Kim, T. (2000): A Study on the Income Analysis of the Elderly and the Improvement of Income Security System. Seoul: Korea Institute for Health and Social Affairs.

Tobin, J. (1958): Estimation of Relationships for Limited Dependent Variables. Econometrica 26(1): 24-36. Tuma, N.B. (1982): Nonparametric and Partially Parametric Approaches to Event-History Analysis. Sociological Methodology 13: 1-60.

Visco, I. (2002): Ageing Populations: Economic Issues and Policy Challenges. Berlin: Springer.

Won, J. - Kim, J. - Jeon, B. - Woo, S. (2008): The Labour Supply of the Elderly and Tax and Fiscal Policies. Seoul: Korea Institute of Public Finance.

Yeo, Y. - Heshmati, A. (2014): Healthy Residential Environments for the Elderly. Journal of Housing for the Elderly 28(1): 1-20.

Open Access. This is an open-access article distributed under the terms of the Creative Commons Attribution-NonCommercial 4.0 International License (https://creativecommons.org/licenses/by-nc/4.0/), which permits unrestricted use, distribution, and reproduction in any medium for non-commercial purposes, provided the original author and source are credited, a link to the CC License is provided, and changes - if any - are indicated. 